\title{
Plant Frataxin in Metal Metabolism
}

\author{
Diego F. Gomez-Casati*, Maria V. Busi and Maria A. Pagani \\ Centro de Estudios Fotosintéticos y Bioquímicos (CEFOBI-CONICET), Universidad Nacional de Rosario, Rosario, Argentina
}

Frataxin is a highly conserved protein from prokaryotes to eukaryotes. Several functions related to iron metabolism have been postulated for this protein, including Fe-S cluster and heme synthesis, response to oxidative damage and oxidative phosphorylation. In plants, the presence of one or two isoforms of this protein with dual localization in mitochondria and chloroplasts has been reported. Frataxin deficiency affects iron metabolism in both organelles, leading to an impairment of mitochondrial respiration, and chlorophyll and photosynthetic electron transport deficiency in chloroplasts. In addition, plant frataxins can react with $\mathrm{Cu}^{2+}$ ions and dimerize, which causes the reduction of free $\mathrm{Cu}$ ions. This could provide an additional defense mechanism against the oxidation of Fe-S groups by $\mathrm{Cu}$ ions. While there is a consensus on the involvement of frataxin in iron homeostasis in most organisms, the interaction of plant frataxins with Cu ions, the presence of different isoforms, and/or the localization in two plant organelles suggest that this protein might have additional functions in vegetal tissues.

Felipe Klein Ricachenevsky, Universidade Federal de Santa Maria,

Brazil

Reviewed by: Khurram Bashir,

RIKEN, Japan

Daniel H. Gonzalez,

National University of the Littoral,

Argentina

Joaquin Medina

Centro de Biotecnología y Genómica de Plantas (CBGP), Spain

*Correspondence:

Diego F. Gomez-Casati gomezcasati@cefobi-conicet.gov.ar

Specialty section: This article was submitted to Plant Nutrition,

a section of the journal

Frontiers in Plant Science

Received: 30 May 2018 Accepted: 02 November 2018 Published: 21 November 2018

Citation:

Gomez-Casati DF, Busi MV and Pagani MA (2018) Plant Frataxin in Metal Metabolism.

Front. Plant Sci. 9:1706. doi: 10.3389/fpls.2018.01706
Keywords: frataxin, iron, copper, Fe-S clusters, metal homeostasis

\section{IRON FUNCTIONS IN PLANTS, UPTAKE AND DISTRIBUTION}

Iron is an essential element for almost all life forms. It is part of cofactors that carry out electron transfer functions, and is involved in chemical transitions (e.g., hydroxylations), hydration and dehydration reactions and radical-mediated rearrangements. Iron also participates in oxygen sensing and transport, and regulation of protein stability (Connorton et al., 2017). Iron is essential for plant growth but, at the same time, is highly reactive and toxic via the Fenton reaction. Thus, plants tightly control iron homeostasis and react to both deficiency and overload of iron. Photosynthetic organisms are distinguished by a high iron requirement for the function of both mitochondria and chloroplasts. These organelles are thought to play a major role in the iron metabolism of the plant cell because this metal/ion serves as an essential cofactor for many enzymes involved in the mitochondrial respiratory chain and electron transfer in the chloroplastic photosynthetic complexes (Morrissey and Guerinot, 2009).

Plants mainly acquire iron from the rhizosphere. Although iron is one of the most abundant metals in the land surface, its availability for plant roots is very low, dependent on the soil reduction potential and $\mathrm{pH}$. In soils that are aerobic or at higher $\mathrm{pH}, \mathrm{Fe}$ is readily oxidized and is thus predominately in the form of insoluble ferric $\mathrm{Fe}(\mathrm{III})$ oxides. At lower $\mathrm{pH}$, the ferric ion is freed from the oxide and becomes more available for uptake. Thirty percent of the world's land for cultivation is too alkaline for optimal plant growth - the most common problem is iron deficiency. Many plant foods like rice, maize, and wheat constitute poor sources of dietary iron (Takahashi et al., 2001; Walker and Connolly, 2008; Morrissey and Guerinot, 2009).

Iron uptake in plants has classically been divided into Strategy I (reducing, dicotyledonous and non-graminaceous monocots) and Strategy II (chelating, graminaceous monocots), the main 
difference being the oxidation state of the iron (Romheld and Marschner, 1986). In the rhizosphere, iron is mostly found as ferric oxyhydrates of very low solubility. The participation of FRO2 (Ferric Reduction Oxidase 2), IRT1 (Iron-Regulated Transporter 1) and AHA2 (a proton pump located in plasma membrane) has been reported in Strategy I in tomato and Arabidopsis thaliana. Phytosiderophores (plant-derived small organic molecules with a high affinity for iron) and oligopeptide transporters participate in Strategy II in rice, maize and barley (including the iron-siderophore transporters YS1, first characterized in maize, and YSL15 in rice) (Higuchi et al., 1999; Curie et al., 2001; Inoue et al., 2009; Nozoye et al., 2011). Rice is particular among monocots because it uses Strategy II to acquire Fe from rhizosphere but also has the Strategy I-like system (Ishimaru et al., 2006). Under flooded conditions, when Fe(II) is more stable and abundant, rice also absorbs $\mathrm{Fe}$ (II) directly via OsIRT1 (Oryza sativa IRT1) and OsNRAMPs (Natural Resistance Associated Macrophage Proteins) (Takahashi et al., 2011). It has been reported that IRT1 has a major role in the regulation of plant iron homeostasis and it is essential for plant growth under iron-limited conditions (Vert et al., 2002). IRT1 undergoes ubiquitin-dependent endocytosis to prevent the uptake of other divalent metals such as Mn, Zn, and Co (Barberon et al., 2014; Dubeaux et al., 2015). In addition, other transporters such as several NRAMPs also participate in the uptake of iron, but as a low-affinity systems (Curie et al., 2000; Castaings et al., 2016).

Several phenylpropanoid-pathway enzymes are upregulated under iron deficiency in Arabidopsis such as PAL1, PAL2 (two Phe ammonia-lyases), 4CL1 and 4CL2 (two 4-coumarate:CoA ligases), the $\mathrm{ABC}$ transporter PDR9 (responsible for coumarin secretion into the rhizosphere) and MAT3 (an enzyme that produces $S$-adenosyl methionine which is involved in coumarin biosynthesis) (Lan et al., 2011; Rodriguez-Celma et al., 2013; Mai et al., 2016). It has been demonstrated that the phenolic compounds secreted facilitate Fe(III) availability for the FRO2 reductase to generate $\mathrm{Fe}(\mathrm{II})$ which is transported by IRT1 (Fourcroy et al., 2016). This suggests that these phenolic compounds are important in/for Strategy I iron uptake and are also involved in iron mobilization from insoluble pools (soil) or root apoplast (Fourcroy et al., 2014; Schmid et al., 2014). The catecholic coumarins found at the highest levels in the exudates of iron-deficient wild-type Arabidopsis are esculetin, fraxetin, scopoletin, and sideretin (Fourcroy et al., 2014; Schmid et al., 2014). Fraxetin is the major coumarin exuded into the rhizosphere in response to iron deficiency in alkaline conditions, while sideretin is exuded in acidic conditions. Fraxetin and sideretin are synthesized from scopoletin by hydroxylases [2-ODD (S8H)], which generates fraxetin, and a cytochrome P450 (CYP82C4), which oxidizes fraxetin to generate sideretin) and both compounds efficiently mobilize and reduce insoluble $\mathrm{Fe}(\mathrm{III})$, rescuing the chlorotic phenotypes (Rajniak et al., 2018). To date, most efforts in understanding soil iron-uptake limitations have focused on the role of soil $\mathrm{pH}$ and have ignored other potentially relevant factors such as interactions with soil organic matter or other metals such as $\mathrm{Zn}$ (II) or $\mathrm{Mn}$ (II) (Rajniak et al., 2018).
Because of its low solubility and high toxicity, iron must form complexes with chelators to be translocated without causing damage by redox reactions (Dubeaux et al., 2015). One of the complexes necessary for transport by the symplast occurs between the reduced form of iron $\left(\mathrm{Fe}^{2+}\right)$ and nicotianamine, a non-protein amino acid produced by nicotianamine synthase (Inoue et al., 2003; Klatte et al., 2009; Rellan-Alvarez et al., 2010), which also chelates other divalent cations (e.g., $\mathrm{Zn}^{2+}$ ). Once iron has passed the endodermis, it is taken into the xylem to reach the shoot. The dominant form of iron in the xylem is $\mathrm{Fe}^{3+}$ bound to citrate and, therefore, the flow of citrate is essential for iron translocation (Rellan-Alvarez et al., 2010). This translocation is mediated by the efflux transporter FRD3 in Arabidopsis (Green and Rogers, 2004) and its ortholog FRDL1 in rice (Yokosho et al., 2016).

The leaves are the main receptor organ for iron because they are where it is needed for photosynthesis. Here, iron reenters the symplast by the action of FRO proteins (Finazzi et al., 2015; Bashir et al., 2016). Subsequently, it can be remobilized and arrives at other sink organs through the phloem, where it is mainly transported as Fe(II)- nicotianamine complexes. In Arabidopsis, OPT3 (of the oligopeptide transporter family protein) is involved in this process (Mendoza-Cozatl et al., 2014; Zhai et al., 2014). The seed is considered the final destination of iron, where iron reserves are fundamental for germination. The YSL transporters are involved in the iron loading of the seeds (Le Jean et al., 2005).

Mitochondria and chloroplasts represent major iron sinks within cells, as iron is required for the proper functioning of the respiratory chain and photosynthetic protein complexes. The mechanisms by which Fe is obtained by chloroplasts and mitochondria are not as well-known as iron uptake at the root epidermis. There is evidence of reduction-based mechanisms for chloroplast and mitochondria Fe-acquisition, since the presence of FRO7 and FRO3/FRO8 has been reported in each organelle (Jeong et al., 2008). A mitochondrial iron transporter, which belongs to the mitochondrial carrier family (MCF) also present in yeast, zebrafish, humans, and Drosophila, was identified in rice and named MIT (Bashir et al., 2011). The protein PIC1 (Permease In Chloroplasts 1) was the first molecular component involved in plastid Fe-transport identified in Arabidopsis and tobacco (Duy et al., 2007; Gong et al., 2015). In addition, other proteins are supposed to participate in $\mathrm{Fe}$ transport across the chloroplast envelope, including two transporters from the yellow stripe 1-like family, YSL4 and YSL6, which have been characterized as potential plastid Fe-efflux transporters in Arabidopsis (Divol et al., 2013). However, in summary, mitochondrial and chloroplast iron transport is till far from being completely deciphered, nor it is understood their cross talk regarding iron homeostasis.

\section{BIOSYNTHESIS OF IRON COFACTORS: THE PARTICIPATION OF FRATAXIN}

Iron is an important component of Fe-S clusters found in many ferrosulfoproteins. Three different systems capable of mediating 
Fe-S cluster assembly have been identified: NIF (nitrogen fixation) found in azeotropic bacteria, SUF (mobilization of sulfur) found in archaea, bacteria and plastids, and ISC (ironsulfur cluster) present in bacteria and mitochondria (Romheld and Marschner, 1983; Patzer and Hantke, 1999; Dos Santos et al., 2004; Lill and Muhlenhoff, 2008; Morrissey and Guerinot, 2009; Balk and Pilon, 2011). These systems have in common three steps: (i) the production of sulfur from cysteine, catalyzed by a cysteine desulfurase; (ii) the assembly of Fe-S clusters onto scaffold proteins; and (iii) the transfer of the mature Fe$\mathrm{S}$ cluster into an apoprotein. It has been reported that a small mitochondrial protein, frataxin, could be involved in several steps of this process (Balk and Lobreaux, 2005; Lill and Muhlenhoff, 2008; Lillig and Lill, 2009; Balk and Pilon, 2011; Turowski et al., 2012).

Frataxin is a nuclear-encoded mitochondrial protein whose deficiency is the cause of Friedreich's ataxia, a hereditary cardioand neurodegenerative disease in humans. This protein plays a role in $\mathrm{Fe}-\mathrm{S}$ cluster biosynthesis, protection against oxidative stress and iron metabolism. Frataxin is highly conserved throughout evolution, being present in humans, plants, flies, worms, and bacteria (Gibson et al., 1996; Babcock et al., 1997; Adinolfi et al., 2002; Busi and Gomez-Casati, 2012; Han et al., 2017). Some hints about frataxin function can be gleaned from the evolutionary record (Morrissey and Guerinot, 2009). The appearance of frataxin in eukaryotes occurred about the time of the endosymbiotic event creating mitochondria from the purple bacterial ancestor, and it was probably acquired by mitochondria together with other components of the ISC operon (Waters et al., 2007; Morrissey and Guerinot, 2009). Different organisms developed mechanisms to avoid the toxicity of free metal ions that allow the control of their uptake, storage and release. It was postulated that frataxin potentially fulfills some of these functions (Busi and Gomez-Casati, 2012).

In 2004, we identified the first frataxin protein in a photosynthetic organism, A. thaliana (Busi et al., 2004, 2006). The functionality of AtFH was assessed by complementation of a yeast frataxin-null mutant, suggesting that AtFH was involved in plant mitochondrial respiration and stress responses (Busi et al., 2004). In agreement with this hypothesis, AtFH-deficient plants presented retarded growth, showed an increment of reactive oxygen species (ROS) and an induction of oxidative stress markers. Interestingly, we also found an increment of aconitase and succinate dehydrogenase-2 (SDH2-1) transcripts, both coding for mitochondrial Fe-S-containing proteins. The reduction of the activities of both enzymes indicates that $\mathrm{AtFH}$ also participates in Fe-S cluster assembly or the insertion of $\mathrm{Fe}-\mathrm{S}$ clusters into apoproteins, possibly in cooperation with other proteins such as Nfs1, HscB, Isd11, and Isu (among others), by the formation of a multiprotein complex (GonzalezCabo et al., 2005; Busi et al., 2006; Maliandi et al., 2007; Shan et al., 2007; Shan and Cortopassi, 2012; Turowski et al., 2012; Leaden et al., 2014; Figure 1). Consistent with the essential role of $\mathrm{AtFH}$ in cellular function is the observation that homozygous null mutants result in a lethal phenotype (Busi et al., 2004, 2006; Vazzola et al.,
2007; Martin et al., 2009). Our data also substantiate the hypothesis that AtFH, apart from its role in protecting bioavailable iron within mitochondria and the biogenesis of $\mathrm{Fe}-\mathrm{S}$ groups, plays a role in the biosynthesis of heme in plants (Maliandi et al., 2011). We have shown, by in vitro experiments, that AtFH catalyzes the formation of heme when it is incubated with $\mathrm{Fe}$ (II) and protoporphyrin IX (Armas et al., 2019). Despite plant ferrochelatases are only present in chloroplasts (Lister et al., 2001; Masuda et al., 2003), a modest but detectable ferrochelatase activity has been observed in plant mitochondria (Cornah et al., 2002), pointing toward frataxin as the enzyme responsible for the reaction in this organelle.

We have reported that in Arabidopsis, AtFH is dualtargeted to mitochondria and chloroplasts (Turowski et al., 2015) and its deficiency alters the normal functioning of chloroplasts by affecting the levels of $\mathrm{Fe}$, chlorophyll, and $\mathrm{Fe}$ $S$ proteins, suggesting that AtFH plays a role as a modulator of both the mitochondrial ISC and chloroplast SUF systems (Turowski et al., 2015; Figure 1). In AtFH deficient plants, we also found a reduction of about $40 \%$ in ferredoxin levels and about $30 \%$ in nitrite reductase (a chloroplastic Fe-Scontaining protein) activity (Turowski et al., 2015). Thus, it is possible that plant frataxins play similar roles in the two organelles, as iron donors, regulating the activity of $\mathrm{Fe}-\mathrm{S}$ proteins, and, possibly, modulating the activity of the ISC and SUF systems.

Although we identified only one frataxin gene in A. thaliana, other plants could have at least two isoforms (Murgia et al., 2009). Recently, we reported the presence of two functional frataxin isoforms in Zea mays, $\mathrm{ZmFH}-1$ and $\mathrm{ZmFH}-2$, located in both, mitochondria and chloroplasts (Buchensky et al., 2017). The biochemical, biophysical and physiological studies showed some differences between the two isoforms in protection against oxidants, aggregation state and expression patterns. ZmFH-1 showed to be more efficient against oxidative damage and it is expressed in a higher extent in almost all tissues respect to $\mathrm{ZmFH}$ 2. Furthermore, $\mathrm{ZmFH}-2$ undergoes some conformational changes when exposed to air, possibly due to a C-terminal extension that could give high thermodynamic stability to the protein in comparison to $\mathrm{ZmFH}-1$ (Buchensky et al., 2017; Sanchez et al., 2018). These results suggest that the two proteins play similar but not identical roles in plant cell metabolism.

In some cases, frataxin assembly seems to be a consequence of iron incorporation into the protein. The assembly of yeast frataxin, for instance, seems to be driven by iron oxidation and accumulation by iron core formation, whereas iron core degradation results in protein disassembly (Adamec et al., 2000; Aloria et al., 2004). Human frataxin assembly has been proposed to be a means of detoxifying redox-active iron. However, in the case of human frataxin, iron does not seem to be the main factor for assembly and it was postulated that the assembly is a physiological property of the protein that allows it to perform diverse cellular functions (O'Neill et al., 2005a,b). 

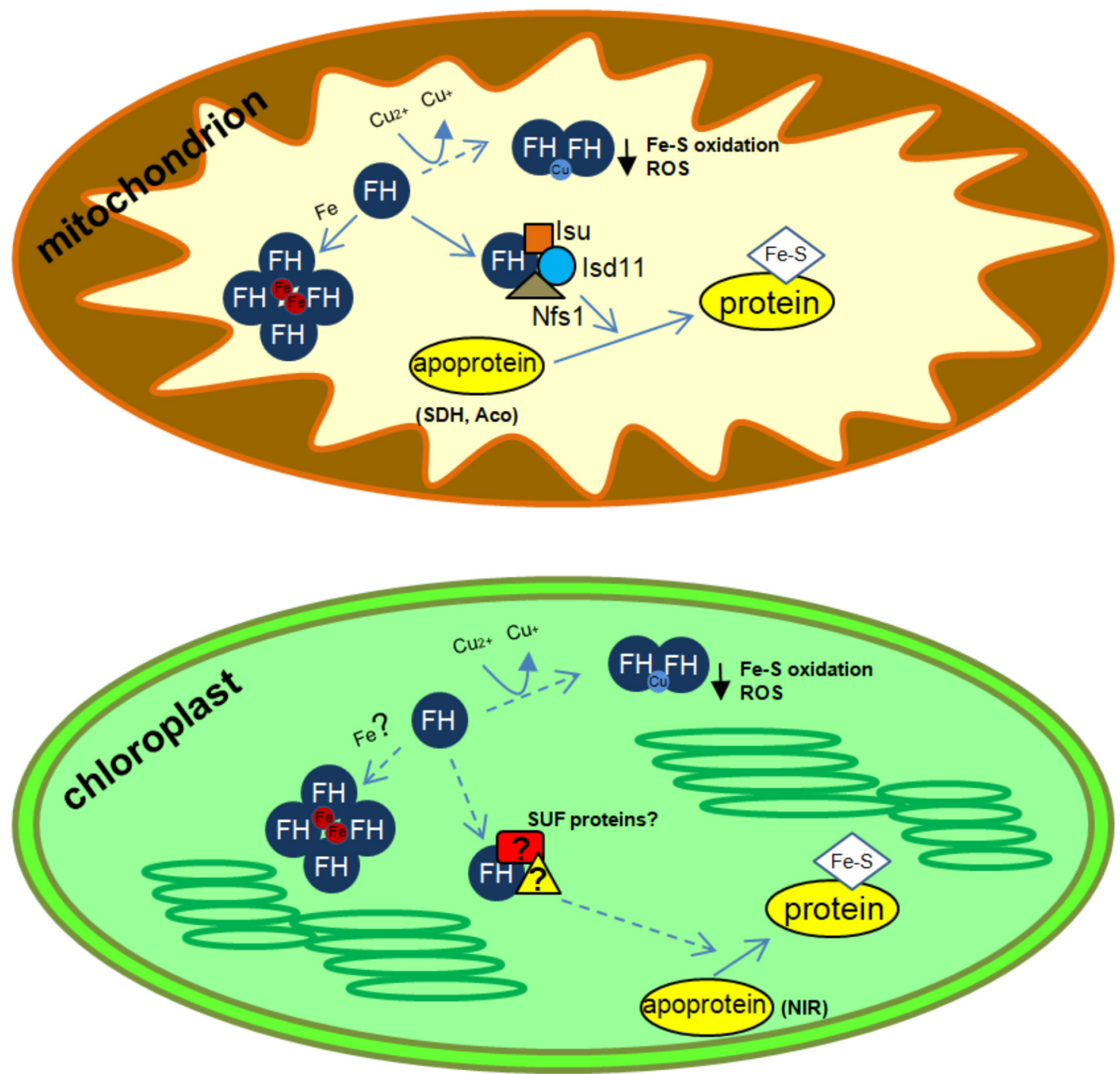

FIGURE 1 | Schematics of possible frataxin functions in plant organelles. ROS, reactive oxygen species; SDH, succinate dehydrogenase; Aco, aconitase; NIR, nitrite reductase. In mitochondria, frataxin increase Nfs1 activity and could also be involved in several additional functions related to iron and copper metabolism (iron storage, Fe-S protein maturation and prevention of ROS formation after Cu reduction). In chloroplasts, frataxin could be involved in metal metabolism and Fe-S synthesis, possibly by the interaction with proteins from the SUF system. In addition, frataxin could also be involved in Cu reduction and response to Fe-S cluster oxidation and in the prevention of ROS accumulation. Known frataxin functions are indicated with solid arrows, whereas possible functions are indicated with dashed arrows.

\section{FRATAXIN AND COPPER}

$\mathrm{Cu}$ is a trace element necessary for many different processes in plants. More than $50 \%$ of $\mathrm{Cu}$ present in plants is found in chloroplasts, which underscores the need for $\mathrm{Cu}$ in photosynthesis (Raldugina et al., 2016). The major $\mathrm{Cu}$ protein is plastocyanin, which is an essential component of the electron transport chain of photosystem I (Schubert et al., 2002; Kramer and Clemens, 2006). Plant mitochondria also require $\mathrm{Cu}$ for the assembly and function of cytochrome $c$ oxidase, the terminal enzyme of the respiratory chain, among other $\mathrm{Cu}$ proteins (Garcia et al., 2014). Nevertheless, free copper ions are dangerous inside cells since they can directly attack functional sites in proteins or induce ROS production through Fenton and Haver-Weiss reactions (Halliwell, 2006). As a result, many protective mechanisms exist, such as $\mathrm{Cu}$ metallochaperones (Robinson and Winge, 2010), low molecular weight thiol ligands such as glutathione, and the mitochondrial anionic compound known as copper ligand (or CuL) described in yeast (Cobine et al., 2004). Still, $\mathrm{Cu}$ is toxic when present in excess, probably because these housekeeping defense mechanisms are overwhelmed.

Copper toxicity has classically been associated with ROS production and oxidative damage. However, more recent evidence shows that damage and inhibition of Fe-S metabolism is the more likely initial manifestation of $\mathrm{Cu}$ toxicity (Dupont et al., 2011). Dehydratase family enzymes are rapidly inactivated 
upon exposure of Escherichia coli cells to low micromolar copper levels due to the displacement of iron atoms from their solventexposed Fe-S clusters (Macomber et al., 2007). Copper stress in Bacillus subtilis leads to enhanced expression of Fe-S cluster scaffold (SufU) and many Fe-S proteins, as well as iron and sulfur uptake pathways (Chillappagari et al., 2010). Additional work performed in vitro confirms that mammalian ISCA1/2 and GLRX5 Fe-S clusters are destabilized by the presence of $\mathrm{Cu}(\mathrm{I})$ (Brancaccio et al., 2017).

De novo $\mathrm{Fe}-\mathrm{S}$ cluster biogenesis in plants occurs in chloroplasts and mitochondria and as we mentioned above, plant frataxins are located in both organelles (Turowski et al., 2015; Buchensky et al., 2017). We have shown that frataxins can react in vitro with the free cupric ion to give the cuprous form (Sanchez et al., 2018). In this reaction, the conserved cysteine residue of frataxin is oxidized forming a disulfide bridge with another frataxin unit (Buchensky et al., 2017). Moreover, plant frataxins oxidized and in their dimeric form (AtFH and $\mathrm{ZmFH} 2$ ) can bind free $\mathrm{Cu}(\mathrm{I})$ ions (Sanchez et al., 2018). Frataxin oxidation and the resulting dimerization might be necessary to bring together enough ligands for the cuprous ion. $\mathrm{Cu}(\mathrm{I})$ binding sites are dominated by amino acids with sulfur ligands like cysteine and methionine, but histidine can also bind $\mathrm{Cu}(\mathrm{I})$, although less tightly. The cuprous ion is coordinated by 2,3 , or 4 ligands, and proteins involved in copper resistance tend to have a coordination environment of low affinity and high coordination number (usually 4) (Rubino and Franz, 2012). AtFH and ZmFH-2 contain three histidine and two methionine residues (the cysteine residue is oxidized and unable to bind copper). Among the potential plant frataxin $\mathrm{Cu}(\mathrm{I})$ ligands, two histidine residues are relatively close (seven and eight amino acids apart in $\mathrm{ZmFH}-2$ and AtFH, respectively). In this manner, a plant frataxin dimer might fulfill the requirements of four lowaffinity ligands for a $\mathrm{Cu}(\mathrm{I})$ ion. The reaction observed in vitro might reasonably occur in vivo, with concomitant reduction of free copper ions, hence protecting the Fe-S clusters in plants. In this way, frataxins could comprise an additional defense for Fe-S clusters in the presence of excess copper (Figure 1).

\section{REFERENCES}

Adamec, J., Rusnak, F., Owen, W. G., Naylor, S., Benson, L. M., Gacy, A. M., et al. (2000). Iron-dependent self-assembly of recombinant yeast frataxin: implications for Friedreich ataxia. Am. J. Hum. Genet. 67, 549-562. doi: 10. 1086/303056

Adinolfi, S., Trifuoggi, M., Politou, A. S., Martin, S., and Pastore, A. (2002). A structural approach to understanding the iron-binding properties of phylogenetically different frataxins. Hum. Mol. Genet. 11, 1865-1877. doi: 10. 1093/hmg/11.16.1865

Aloria, K., Schilke, B., Andrew, A., and Craig, E. A. (2004). Iron-induced oligomerization of yeast frataxin homologue $\mathrm{Yfh} 1$ is dispensable in vivo. EMBO Rep. 5, 1096-1101. doi: 10.1038/sj.embor.7400272

Armas, A. M., Balparda, M., Terenzi, A., Busi, M. V., Pagani, M. A., and GomezCasati, D. F. (2019). Ferrochelatase activity of plant frataxin. Biochimie 156, 118-122. doi: 10.1016/j.biochi.2018.10.009

Babcock, M., De Silva, D., Oaks, R., Davis-Kaplan, S., Jiralerspong, S., Montermini, L., et al. (1997). Regulation of mitochondrial iron accumulation
There is additional evidence from different organisms that frataxin might be involved in copper metabolism. Friedreich's ataxia patients show altered $\mathrm{Cu}$ distribution in the dentate nucleus of the central nervous system (Koeppen et al., 2012), and in the Drosophila model of the disease there is a generalized increase in copper content (Soriano et al., 2016), as there is in mitochondria of yeast frataxin-null mutants (Han et al., 2017). Moreover, in frataxin knockdown flies, treatment with copper chelators improved their impaired motor performance without altering the iron accumulation phenotype, implying a direct role of $\mathrm{Cu}$ in the pathophysiology of the disease (Soriano et al., 2016).

Saccharomyces cerevisiae frataxin-null mutants are more sensitive to $\mathrm{Cu}$ than wild-type cells (Foury and Cazzalini, 1997; Han et al., 2017) and in anaerobic growth conditions, in which little oxygen is available for ROS generation, copper accumulation and its toxicity increases (Strain and Culotta, 1996; Outten et al., 2001). Ha-Duong and coworkers have shown that yeast frataxin can bind $\mathrm{Cu}(\mathrm{II})$ and $\mathrm{Cu}(\mathrm{I})$ ions, with higher affinities than iron (Han et al., 2017). Thus, we might assume that yeast frataxin protects $\mathrm{Fe}-\mathrm{S}$ clusters from copper toxicity by preventing free $\mathrm{Cu}$ ions from interacting with them in the same way we have suggested for plant frataxins. Yeast complementation assays with plant frataxins support this hypothesis. Arabidopsis and maize frataxins can completely restore the ability of a $S$. cerevisiae frataxin-null strain to grow in high copper medium (Sanchez et al., 2018), which led us to infer that plant and yeast frataxins might perform similar and conserved molecular functions in copper metabolism.

\section{AUTHOR CONTRIBUTIONS}

DG-C, MB, and MP collaborated in the writing of the manuscript.

\section{FUNDING}

This work was supported by grants from ANPCyT (PICT 20142184/2016-350/2016-0264). DG-C, MB, and MP are research members of CONICET.

by Yfhlp, a putative homolog of frataxin. Science 276, 1709-1712. doi: 10.1126/ science.276.5319.1709

Balk, J., and Lobreaux, S. (2005). Biogenesis of iron-sulfur proteins in plants. Trends Plant Sci. 10, 324-331. doi: 10.1016/j.tplants.2005.05.002

Balk, J., and Pilon, M. (2011). Ancient and essential: the assembly of iron-sulfur clusters in plants. Trends Plant Sci. 16, 218-226. doi: 10.1016/j.tplants.2010.1 2.006

Barberon, M., Dubeaux, G., Kolb, C., Isono, E., Zelazny, E., and Vert, G. (2014). Polarization of IRON-REGULATED TRANSPORTER 1 (IRT1) to the plant-soil interface plays crucial role in metal homeostasis. Proc. Natl. Acad. Sci. U.S.A. 111, 8293-8298. doi: 10.1073/pnas.14022 62111

Bashir, K., Ishimaru, Y., Shimo, H., Nagasaka, S., Fujimoto, M., Takanashi, H., et al. (2011). The rice mitochondrial iron transporter is essential for plant growth. Nat. Commun. 2:322. doi: 10.1038/ncomms1326

Bashir, K., Rasheed, S., Kobayashi, T., Seki, M., and Nishizawa, N. K. (2016). Regulating subcellular metal homeostasis: the key to crop improvement. Front. Plant Sci. 7:1192. doi: 10.3389/fpls.2016.01192 
Brancaccio, D., Gallo, A., Piccioli, M., Novellino, E., Ciofi-Baffoni, S., and Banci, L. (2017). [4Fe-4S] cluster assembly in mitochondria and its impairment by copper. J. Am. Chem. Soc. 139, 719-730. doi: 10.1021/jacs.6b09567

Buchensky, C., Sanchez, M., Carrillo, M., Palacios, O., Capdevila, M., DominguezVera, J. M., et al. (2017). Identification of two frataxin isoforms in Zea mays: structural and functional studies. Biochimie 140, 34-47. doi: 10.1016/j.biochi. 2017.06.011

Busi, M. V., and Gomez-Casati, D. F. (2012). Exploring frataxin function. IUBMB Life 64, 56-63. doi: 10.1002/iub.577

Busi, M. V., Maliandi, M. V., Valdez, H., Clemente, M., Zabaleta, E. J., Araya, A., et al. (2006). Deficiency of Arabidopsis thaliana frataxin alters activity of mitochondrial Fe-S proteins and induces oxidative stress. Plant J. 48, 873-882. doi: 10.1111/j.1365-313X.2006.02923.x

Busi, M. V., Zabaleta, E. J., Araya, A., and Gomez-Casati, D. F. (2004). Functional and molecular characterization of the frataxin homolog from Arabidopsis thaliana. FEBS Lett. 576, 141-144. doi: 10.1016/j.febslet.2004.09.003

Castaings, L., Caquot, A., Loubet, S., and Curie, C. (2016). The high-affinity metal transporters NRAMP1 and IRT1 team up to take up iron under sufficient metal provision. Sci. Rep. 6:37222. doi: 10.1038/srep37222

Chillappagari, S., Seubert, A., Trip, H., Kuipers, O. P., Marahiel, M. A., and Miethke, M. (2010). Copper stress affects iron homeostasis by destabilizing iron-sulfur cluster formation in Bacillus subtilis. J. Bacteriol. 192, 2512-2524. doi: 10.1128/JB.00058-10

Cobine, P. A., Ojeda, L. D., Rigby, K. M., and Winge, D. R. (2004). Yeast contain a non-proteinaceous pool of copper in the mitochondrial matrix. J. Biol. Chem. 279, 14447-14455. doi: 10.1074/jbc.M312693200

Connorton, J. M., Balk, J., and Rodriguez-Celma, J. (2017). Iron homeostasis in plants - a brief overview. Metallomics 9, 813-823. doi: 10.1039/c7mt00136c

Cornah, J. E., Roper, J. M., Pal Singh, D., and Smith, A. G. (2002). Measurement of ferrochelatase activity using a novel assay suggests that plastids are the major site of haem biosynthesis in both photosynthetic and non-photosynthetic cells of pea (Pisum sativum L.). Biochem. J. 362, 423-432. doi: 10.1042/bj3620423

Curie, C., Alonso, J. M., Le Jean, M., Ecker, J. R., and Briat, J. F. (2000). Involvement of NRAMP1 from Arabidopsis thaliana in iron transport. Biochem. J. 347(Pt 3), 749-755. doi: 10.1042/bj3470749

Curie, C., Panaviene, Z., Loulergue, C., Dellaporta, S. L., Briat, J. F., and Walker, E. L. (2001). Maize yellow stripel encodes a membrane protein directly involved in Fe(III) uptake. Nature 409, 346-349. doi: 10.1038/35053080

Divol, F., Couch, D., Conejero, G., Roschzttardtz, H., Mari, S., and Curie, C. (2013). The Arabidopsis YELLOW STRIPE LIKE4 and 6 transporters control iron release from the chloroplast. Plant Cell 25, 1040-1055. doi: 10.1105/tpc. 112.107672

Dos Santos, P. C., Dean, D. R., Hu, Y., and Ribbe, M. W. (2004). Formation and insertion of the nitrogenase iron-molybdenum cofactor. Chem. Rev. 104, 1159-1173. doi: 10.1021/cr0206081

Dubeaux, G., Zelazny, E., and Vert, G. (2015). Getting to the root of plant iron uptake and cell-cell transport: polarity matters! Commun. Integr. Biol. 8:e1038441. doi: 10.1080/19420889.2015.1038441

Dupont, C. L., Grass, G., and Rensing, C. (2011). Copper toxicity and the origin of bacterial resistance-new insights and applications. Metallomics 3, 1109-1118. doi: 10.1039/c1mt00107h

Duy, D., Wanner, G., Meda, A. R., Von Wiren, N., Soll, J., and Philippar, K. (2007). PIC1, an ancient permease in Arabidopsis chloroplasts, mediates iron transport. Plant Cell 19, 986-1006. doi: 10.1105/tpc.106.047407

Finazzi, G., Petroutsos, D., Tomizioli, M., Flori, S., Sautron, E., Villanova, V., et al. (2015). Ions channels/transporters and chloroplast regulation. Cell Calcium 58, 86-97. doi: 10.1016/j.ceca.2014.10.002

Fourcroy, P., Siso-Terraza, P., Sudre, D., Saviron, M., Reyt, G., Gaymard, F., et al. (2014). Involvement of the ABCG37 transporter in secretion of scopoletin and derivatives by Arabidopsis roots in response to iron deficiency. New Phytol. 201, 155-167. doi: 10.1111/nph.12471

Fourcroy, P., Tissot, N., Gaymard, F., Briat, J. F., and Dubos, C. (2016). Facilitated Fe nutrition by phenolic compounds excreted by the Arabidopsis ABCG37/PDR9 transporter requires the IRT1/FRO2 high-affinity root $\mathrm{Fe}^{2+}$ transport system. Mol. Plant 9, 485-488. doi: 10.1016/j.molp.2015.09.010

Foury, F., and Cazzalini, O. (1997). Deletion of the yeast homologue of the human gene associated with Friedreich's ataxia elicits iron accumulation in mitochondria. FEBS Lett. 411, 373-377. doi: 10.1016/S0014-5793(97)00734-5
Garcia, L., Welchen, E., and Gonzalez, D. H. (2014). Mitochondria and copper homeostasis in plants. Mitochondrion 19(Pt B), 269-274. doi: 10.1016/j.mito. 2014.02.011

Gibson, T. J., Koonin, E. V., Musco, G., Pastore, A., and Bork, P. (1996). Friedreich's ataxia protein: phylogenetic evidence for mitochondrial dysfunction. Trends Neurosci. 19, 465-468. doi: 10.1016/S0166-2236(96)20054-2

Gong, X., Guo, C., Terachi, T., Cai, H., and Yu, D. (2015). Tobacco PIC1 mediates iron transport and regulates chloroplast development. Plant Mol. Biol. Rep. 33, 401-413. doi: 10.1007/s11105-014-0758-5

Gonzalez-Cabo, P., Vazquez-Manrique, R. P., Garcia-Gimeno, M. A., Sanz, P., and Palau, F. (2005). Frataxin interacts functionally with mitochondrial electron transport chain proteins. Hum. Mol. Genet. 14, 2091-2098. doi: 10.1093/hmg/ ddi 214

Green, L. S., and Rogers, E. E. (2004). FRD3 controls iron localization in Arabidopsis. Plant Physiol. 136, 2523-2531. doi: 10.1104/pp.104.045633

Halliwell, B. (2006). Reactive species and antioxidants. Redox biology is a fundamental theme of aerobic life. Plant Physiol. 141, 312-322. doi: 10.1104/ pp.106.077073

Han, T. H. L., Camadro, J. M., Santos, R., Lesuisse, E., El Hage Chahine, J. M., and Ha-Duong, N. T. (2017). Mechanisms of iron and copper-frataxin interactions. Metallomics 9, 1073-1085. doi: 10.1039/c7mt00031f

Higuchi, K., Suzuki, K., Nakanishi, H., Yamaguchi, H., Nishizawa, N. K., and Mori, S. (1999). Cloning of nicotianamine synthase genes, novel genes involved in the biosynthesis of phytosiderophores. Plant Physiol. 119, 471-480. doi: 10.1104/pp.119.2.471

Inoue, H., Higuchi, K., Takahashi, M., Nakanishi, H., Mori, S., and Nishizawa, N. K. (2003). Three rice nicotianamine synthase genes, OsNAS1, OsNAS2, and OsNAS3 are expressed in cells involved in long-distance transport of iron and differentially regulated by iron. Plant J. 36, 366-381. doi: 10.1046/j.1365-313X. 2003.01878.x

Inoue, H., Kobayashi, T., Nozoye, T., Takahashi, M., Kakei, Y., Suzuki, K., et al. (2009). Rice OsYSL15 is an iron-regulated iron(III)-deoxymugineic acid transporter expressed in the roots and is essential for iron uptake in early growth of the seedlings. J. Biol. Chem. 284, 3470-3479. doi: 10.1074/jbc.M806042200

Ishimaru, Y., Suzuki, M., Tsukamoto, T., Suzuki, K., Nakazono, M., Kobayashi, T., et al. (2006). Rice plants take up iron as an $\mathrm{Fe}^{3+}$-phytosiderophore and as $\mathrm{Fe}^{2+}$. Plant J. 45, 335-346. doi: 10.1111/j.1365-313X.2005.02624.x

Jeong, J., Cohu, C., Kerkeb, L., Pilon, M., Connolly, E. L., and Guerinot, M. L. (2008). Chloroplast Fe(III) chelate reductase activity is essential for seedling viability under iron limiting conditions. Proc. Natl. Acad. Sci. U.S.A. 105, 10619-10624. doi: 10.1073/pnas.0708367105

Klatte, M., Schuler, M., Wirtz, M., Fink-Straube, C., Hell, R., and Bauer, P. (2009). The analysis of Arabidopsis nicotianamine synthase mutants reveals functions for nicotianamine in seed iron loading and iron deficiency responses. Plant Physiol. 150, 257-271. doi: 10.1104/pp.109.136374

Koeppen, A. H., Ramirez, R. L., Yu, D., Collins, S. E., Qian, J., Parsons, P. J., et al. (2012). Friedreich's ataxia causes redistribution of iron, copper, and zinc in the dentate nucleus. Cerebellum 11, 845-860. doi: 10.1007/s12311-012-0383-5

Kramer, U., and Clemens, S. (2006). Functions and homeostasis of zinc, copper, and nickel in plants. Curr. Genet. 14, 215-271. doi: 10.1007/4735_96

Lan, P., Li, W., Wen, T. N., Shiau, J. Y., Wu, Y. C., Lin, W., et al. (2011). iTRAQ protein profile analysis of Arabidopsis roots reveals new aspects critical for iron homeostasis. Plant Physiol. 155, 821-834. doi: 10.1104/pp.110.169508

Le Jean, M., Schikora, A., Mari, S., Briat, J. F., and Curie, C. (2005). A loss-offunction mutation in AtYSL1 reveals its role in iron and nicotianamine seed loading. Plant J. 44, 769-782. doi: 10.1111/j.1365-313X.2005.02569.x

Leaden, L., Busi, M. V., and Gomez-Casati, D. F. (2014). The mitochondrial proteins AtHscB and AtIsul involved in Fe-S cluster assembly interact with the Hsp70-type chaperon AtHscA2 and modulate its catalytic activity. Mitochondrion 19(Pt B), 375-381. doi: 10.1016/j.mito.2014.11.002

Lill, R., and Muhlenhoff, U. (2008). Maturation of iron-sulfur proteins in eukaryotes: mechanisms, connected processes, and diseases. Annu. Rev. Biochem. 77, 669-700. doi: 10.1146/annurev.biochem.76.052705.162653

Lillig, C. H., and Lill, R. (2009). Lights on iron-sulfur clusters. Chem. Biol. 16, 1213-1214. doi: 10.1016/j.chembiol.2009.12.005

Lister, R., Chew, O., Rudhe, C., Lee, M. N., and Whelan, J. (2001). Arabidopsis thaliana ferrochelatase-I and -II are not imported into Arabidopsis mitochondria. FEBS Lett. 506, 291-295. doi: 10.1016/S0014-5793(01)02925-8 
Macomber, L., Rensing, C., and Imlay, J. A. (2007). Intracellular copper does not catalyze the formation of oxidative DNA damage in Escherichia coli. J. Bacteriol. 189, 1616-1626. doi: 10.1128/JB.01 357-06

Mai, H. J., Pateyron, S., and Bauer, P. (2016). Iron homeostasis in Arabidopsis thaliana: transcriptomic analyses reveal novel FIT-regulated genes, iron deficiency marker genes and functional gene networks. BMC Plant Biol. 16:211. doi: 10.1186/s12870-016-0899-9

Maliandi, M. V., Busi, M. V., Clemente, M., Zabaleta, E. J., Araya, A., and GomezCasati, D. F. (2007). Expression and one-step purification of recombinant Arabidopsis thaliana frataxin homolog (AtFH). Protein Expr. Purif. 51, 157-161. doi: 10.1016/j.pep.2006.06.007

Maliandi, M. V., Busi, M. V., Turowski, V. R., Leaden, L., Araya, A., and GomezCasati, D. F. (2011). The mitochondrial protein frataxin is essential for heme biosynthesis in plants. FEBS J. 278, 470-481. doi: 10.1111/j.1742-4658.2010. 07968.x

Martin, M., Colman, M. J., Gomez-Casati, D. F., Lamattina, L., and Zabaleta, E. J. (2009). Nitric oxide accumulation is required to protect against iron-mediated oxidative stress in frataxin-deficient Arabidopsis plants. FEBS Lett. 583, 542-548. doi: 10.1016/j.febslet.2008. 12.039

Masuda, T., Suzuki, T., Shimada, H., Ohta, H., and Takamiya, K. (2003). Subcellular localization of two types of ferrochelatase in cucumber. Planta 217, 602-609. doi: 10.1007/s00425-003-1019-2

Mendoza-Cozatl, D. G., Xie, Q., Akmakjian, G. Z., Jobe, T. O., Patel, A., Stacey, M. G., et al. (2014). OPT3 is a component of the iron-signaling network between leaves and roots and misregulation of OPT3 leads to an overaccumulation of cadmium in seeds. Mol. Plant 7, 1455-1469. doi: 10.1093/mp/ ssu067

Morrissey, J., and Guerinot, M. L. (2009). Iron uptake and transport in plants: the good, the bad, and the ionome. Chem. Rev. 109, 4553-4567. doi: 10.1021/ cr900112r

Murgia, I., Tarantino, D., and Soave, C. (2009). Mitochondrial iron metabolism in plants: frataxin comes into play. Plant Soil 325, 5-14. doi: 10.1007/s11104-0090038-6

Nozoye, T., Nagasaka, S., Kobayashi, T., Takahashi, M., Sato, Y., Sato, Y., et al. (2011). Phytosiderophore efflux transporters are crucial for iron acquisition in graminaceous plants. J. Biol. Chem. 286, 5446-5454. doi: 10.1074/jbc.M110. 180026

O'Neill, H. A., Gakh, O., and Isaya, G. (2005a). Supramolecular assemblies of human frataxin are formed via subunit-subunit interactions mediated by a non-conserved amino-terminal region. J. Mol. Biol. 345, 433-439.

O’Neill, H. A., Gakh, O., Park, S., Cui, J., Mooney, S. M., Sampson, M., et al. (2005b). Assembly of human frataxin is a mechanism for detoxifying redoxactive iron. Biochemistry 44, 537-545.

Outten, F. W., Huffman, D. L., Hale, J. A., and O'halloran, T. V. (2001). The independent cue and cus systems confer copper tolerance during aerobic and anaerobic growth in Escherichia coli. J. Biol. Chem. 276, 30670-30677. doi: 10.1074/jbc.M104122200

Patzer, S. I., and Hantke, K. (1999). SufS is a NifS-like protein, and SufD is necessary for stability of the [2Fe-2S] FhuF protein in Escherichia coli. J. Bacteriol. 181, 3307-3309.

Rajniak, J., Giehl, R. F. H., Chang, E., Murgia, I., Von Wiren, N., and Sattely, E. S. (2018). Biosynthesis of redox-active metabolites in response to iron deficiency in plants. Nat. Chem. Biol. 14, 442-450. doi: 10.1038/s41589-018-0019-2

Raldugina, G. N., Krasavina, M. S., Lunkova, N. F., and Burmistrova, N. A. (2016). "Transgenesis in plant metal interaction: emerging remediation techniques," in Resistance of Plants to Cu Stress, ed. P. Ahmad (Berlin: Elsevier), 69-114. doi: 10.1016/B978-0-12-803158-2.00 004-7

Rellan-Alvarez, R., Giner-Martinez-Sierra, J., Orduna, J., Orera, I., RodriguezCastrillon, J. A., Garcia-Alonso, J. I., et al. (2010). Identification of a tri-iron(III), tri-citrate complex in the xylem sap of iron-deficient tomato resupplied with iron: new insights into plant iron longdistance transport. Plant Cell Physiol. 51, 91-102. doi: 10.1093/pcp/ pcp 170

Robinson, N. J., and Winge, D. R. (2010). Copper metallochaperones. Annu. Rev. Biochem. 79, 537-562. doi: 10.1146/annurev-biochem-030409-143539
Rodriguez-Celma, J., Lin, W. D., Fu, G. M., Abadia, J., Lopez-Millan, A. F., and Schmidt, W. (2013). Mutually exclusive alterations in secondary metabolism are critical for the uptake of insoluble iron compounds by Arabidopsis and Medicago truncatula. Plant Physiol. 162, 1473-1485. doi: 10.1104/pp.113. 220426

Romheld, V., and Marschner, H. (1983). Mechanism of iron uptake by peanut plants : I. Fe reduction, chelate splitting, and release of phenolics. Plant Physiol. 71, 949-954. doi: 10.1104/pp.71.4.949

Romheld, V., and Marschner, H. (1986). Evidence for a specific uptake system for iron phytosiderophores in roots of grasses. Plant Physiol. 80, 175-180. doi: $10.1104 / p p .80 .1 .175$

Rubino, J. T., and Franz, K. J. (2012). Coordination chemistry of copper proteins: how nature handles a toxic cargo for essential function. J. Inorg. Biochem. 107, 129-143. doi: 10.1016/j.jinorgbio.2011.11.024

Sanchez, M., Palacios, O., Buchensky, C., Sabio, L., Gomez-Casati, D. F., Pagani, M. A., et al. (2018). Copper redox chemistry of plant frataxins. J. Inorg. Biochem. 180, 135-140. doi: 10.1016/j.jinorgbio.2017. 11.020

Schmid, N. B., Giehl, R. F., Doll, S., Mock, H. P., Strehmel, N., Scheel, D., et al. (2014). Feruloyl-CoA 6'-hydroxylase1-dependent coumarins mediate iron acquisition from alkaline substrates in Arabidopsis. Plant Physiol. 164, 160-172. doi: 10.1104/pp.113.22 8544

Schubert, M., Petersson, U. A., Haas, B. J., Funk, C., Schroder, W. P., and Kieselbach, T. (2002). Proteome map of the chloroplast lumen of Arabidopsis thaliana. J. Biol. Chem. 277, 8354-8365. doi: 10.1074/jbc.M10857 5200

Shan, Y., and Cortopassi, G. (2012). HSC20 interacts with frataxin and is involved in iron-sulfur cluster biogenesis and iron homeostasis. Hum. Mol. Genet. 21, 1457-1469. doi: 10.1093/hmg/d dr582

Shan, Y., Napoli, E., and Cortopassi, G. (2007). Mitochondrial frataxin interacts with ISD11 of the NFS1/ISCU complex and multiple mitochondrial chaperones. Hum. Mol. Genet. 16, 929-941. doi: 10.1093/hmg/ddm038

Soriano, S., Calap-Quintana, P., Llorens, J. V., Al-Ramahi, I., Gutierrez, L., Martinez-Sebastian, M. J., et al. (2016). Metal homeostasis regulators suppress FRDA phenotypes in a Drosophila model of the disease. PLoS One 11:e0159209. doi: 10.1371/journal.pone.0159209

Strain, J., and Culotta, V. C. (1996). Copper ions and the regulation of Saccharomyces cerevisiae metallothionein genes under aerobic and anaerobic conditions. Mol. Gen. Genet. 251, 139-145.

Takahashi, M., Nakanishi, H., Kawasaki, S., Nishizawa, N. K., and Mori, S. (2001). Enhanced tolerance of rice to low iron availability in alkaline soils using barley nicotianamine aminotransferase genes. Nat. Biotechnol. 19, 466-469. doi: $10.1038 / 88143$

Takahashi, R., Ishimaru, Y., Senoura, T., Shimo, H., Ishikawa, S., Arao, T., et al. (2011). The OsNRAMP1 iron transporter is involved in Cd accumulation in rice. J. Exp. Bot. 62, 4843-4850. doi: 10.1093/jxb/err136

Turowski, V. R., Aknin, C., Maliandi, M. V., Buchensky, C., Leaden, L., Peralta, D. A., et al. (2015). Frataxin is localized to both the chloroplast and mitochondrion and is involved in chloroplast $\mathrm{Fe}-\mathrm{S}$ protein function in Arabidopsis. PLoS One 10:e0141443. doi: 10.1371/journal.pone.014 1443

Turowski, V. R., Busi, M. V., and Gomez-Casati, D. F. (2012). Structural and functional studies of the mitochondrial cysteine desulfurase from Arabidopsis thaliana. Mol. Plant 5, 1001-1010. doi: 10.1093/mp/sss037

Vazzola, V., Losa, A., Soave, C., and Murgia, I. (2007). Knockout of frataxin gene causes embryo lethality in Arabidopsis. FEBS Lett. 581, 667-672. doi: 10.1016/j. febslet.2007.01.030

Vert, G., Grotz, N., Dedaldechamp, F., Gaymard, F., Guerinot, M. L., Briat, J. F., et al. (2002). IRT1, an Arabidopsis transporter essential for iron uptake from the soil and for plant growth. Plant Cell 14, 1223-1233. doi: 10.1105/tpc.00 1388

Walker, E. L., and Connolly, E. L. (2008). Time to pump iron: iron-deficiencysignaling mechanisms of higher plants. Curr. Opin. Plant Biol. 11, 530-535 doi: $10.1016 /$ j.pbi.2008.06.013

Waters, B. M., Lucena, C., Romera, F. J., Jester, G. G., Wynn, A. N., Rojas, C. L., et al. (2007). Ethylene involvement in the regulation of the $\mathrm{H}(+)$-ATPase CsHA1 
gene and of the new isolated ferric reductase CsFRO1 and iron transporter CsIRT1 genes in cucumber plants. Plant Physiol. Biochem. 45, 293-301. doi: 10.1016/j.plaphy.2007.03.011

Yokosho, K., Yamaji, N., and Ma, J. F. (2016). OsFRDL1 expressed in nodes is required for distribution of iron to grains in rice. J. Exp. Bot. 67, 5485-5494. doi: $10.1093 /$ jxb/erw314

Zhai, Z., Gayomba, S. R., Jung, H. I., Vimalakumari, N. K., Pineros, M., Craft, E., et al. (2014). OPT3 is a phloem-specific iron transporter that is essential for systemic iron signaling and redistribution of iron and cadmium in Arabidopsis. Plant Cell 26, 2249-2264. doi: 10.1105/tpc.114.12 3737
Conflict of Interest Statement: The authors declare that the research was conducted in the absence of any commercial or financial relationships that could be construed as a potential conflict of interest.

Copyright (c) 2018 Gomez-Casati, Busi and Pagani. This is an open-access article distributed under the terms of the Creative Commons Attribution License (CC BY). The use, distribution or reproduction in other forums is permitted, provided the original author(s) and the copyright owner(s) are credited and that the original publication in this journal is cited, in accordance with accepted academic practice. No use, distribution or reproduction is permitted which does not comply with these terms. 